\title{
Food Insecurity in HIV-Hepatitis C Virus Co-infected Individuals in Canada: The Importance of Co-morbidities
}

\author{
Joseph Cox ${ }^{1,2,3}$ - Anne-Marie Hamelin ${ }^{1}$ Taylor McLinden ${ }^{1}$ Erica E. M. Moodie ${ }^{1}$. \\ Aranka Anema ${ }^{4,5} \cdot$ Kathleen C. Rollet-Kurhajec $^{2}$ - Gilles Paradis ${ }^{1}$. \\ Sean B. Rourke ${ }^{6,7,8} \cdot$ Sharon L. Walmsley ${ }^{9,10} \cdot$ Marina B. Klein ${ }^{2}$ Canadian Co-infection \\ Cohort Investigators
}

Published online: 24 February 2016

(c) The Author(s) 2016. This article is published with open access at Springerlink.com

\begin{abstract}
While research has begun addressing food insecurity (FI) in HIV-positive populations, knowledge regarding FI among individuals living with HIV-hepatitis $\mathrm{C}$ virus $(\mathrm{HCV})$ co-infection is limited. This exploratory study examines sociodemographic, socioeconomic, behavioral, and clinical factors associated with FI in a cohort of HIV$\mathrm{HCV}$ co-infected individuals in Canada. We analyzed longitudinal data from the Food Security and HIV-HCV Co-infection Study of the Canadian Co-infection Cohort collected between November 2012-June 2014 at 15 health centres. FI was measured using the Household Food Security Survey Module and classified using Health Canada criteria. Generalized estimating equations were used to assess factors associated with FI. Among 525 participants, $59 \%$ experienced FI at their first study visit (baseline). Protective factors associated with FI $(p<0.05)$ included: enrolment at a Quebec study site (aOR: 0.42, $95 \%$ CI: $0.27,0.67$ ), employment (aOR: $0.55,95 \%$ CI: $0.35,0.87$ ), and average personal monthly income (aOR
\end{abstract}

Electronic supplementary material The online version of this article (doi:10.1007/s10461-016-1326-9) contains supplementary material, which is available to authorized users.

Joseph Cox

joseph.cox@mcgill.ca

1 Department of Epidemiology, Biostatistics and Occupational Health, McGill University, Purvis Hall, 1020 Pine Avenue West, Montreal, QC H3A 1A2, Canada

2 Chronic Viral Illness Service, McGill University Health Centre, Montreal, QC, Canada

3 CIHR Canadian HIV Trials Network, Vancouver, BC, Canada

4 Department of Pediatrics, Harvard Medical School, Boston, MA, USA per $\$ 100$ CAD increase: 0.98, $95 \%$ CI: 0.97, 0.99). Risk factors for FI included: recent injection drug use (aOR: 1.98, $95 \%$ CI: $1.33,2.96)$, trading away food (aOR: 5.23 , $95 \%$ CI: $2.53,10.81$ ), and recent experiences of depressive symptoms (aOR: 2.11, 95 \% CI: 1.48, 3.01). FI is common in this co-infected population. Engagement of co-infected individuals in substance use treatments, harm reduction programs, and mental health services may mitigate FI in this vulnerable subset of the HIV-positive population.

Keywords Food insecurity · HIV · HCV · Co-infection · Canada

\section{Introduction}

Food insecurity (FI) is an important issue in HIV-positive populations [1-4]. FI exists "whenever the availability of nutritionally adequate and safe foods or the ability to acquire acceptable foods in socially acceptable ways is limited or uncertain" (e.g., without resorting to emergency food supplies, scavenging, stealing, and other coping strategies) [5]. A British Columbia study found that FI

5 Department of Medicine, Boston Children's Hospital, Boston, MA, USA

6 Li Ka Shing Knowledge Institute, St. Michael's Hospital, Toronto, ON, Canada

7 The Ontario HIV Treatment Network, Toronto, ON, Canada

8 Department of Psychiatry, University of Toronto, Toronto, ON, Canada

9 Department of Medicine, University of Toronto, Toronto, ON, Canada

10 Division of Infectious Diseases, University Health Network, Toronto, ON, Canada 
among individuals living with HIV exceeded $70 \%$ in 2007-2008, an increase of over $23 \%$ from 1998-1999 [1, 4] when measured using the Radimer/Cornell Questionnaire [6]. Similarly, the prevalence of FI among HIVpositive individuals in Ontario was recently found to be $69 \%$ when measured by the Household Food Security Survey Module (HFSSM) [7]. This is in contrast to the annual estimate of $8 \%$ of Canadian adults who experienced FI between 2007 and 2012 [8].

In HIV-positive populations in Canada and the United States, FI has been associated with sub-optimal combination antiretroviral treatment (cART) adherence [9, 10] and numerous adverse health outcomes, such as: incomplete HIV viral load suppression [11], lower CD4 cell counts [3, 4], and higher rates of mortality [12, 13]. Many pathways have been proposed for FI's affect on these outcomes. For example, it has been suggested that fear or the actual experience of the side effects of cART are exacerbated in the absence of food, affecting treatment adherence [10]. Additionally, biologic mechanisms such as the impact of food on cART pharmacokinetics [11] and subsequent HIV viral load suppression may have a role. Lastly, nutritional deficiencies are associated with immunosuppression and lower CD4 cell counts in individuals experiencing FI [14].

Due to these adverse outcomes, research in the HIVsetting has identified a variety of risk factors for FI, including: younger age, unstable housing, unemployment, low income, illicit drug use, and experiences of depressive symptoms [15-17]. Indeed, the relationship between FI and HIV has been described as a 'vicious cycle' [15, 17] whereby sociodemographic, socioeconomic, behavioral, and clinical risk factors act as drivers of FI, putting individuals at higher risk for adverse health outcomes. These outcomes ultimately affect an individual's ability to acquire food, thereby perpetuating FI [18].

In the aforementioned research involving HIV-positive populations [1, 4, 7], an unknown proportion of study participants may have been co-infected with hepatitis $\mathrm{C}$ virus $(\mathrm{HCV})$. For that reason, findings from these studies may be not generalizable to HIV-HCV co-infected populations and knowledge regarding FI, including estimates of the prevalence and severity of FI, is limited in populations that are known to be living with both viral infections. In Canada, $20 \%$ of the HIV-positive population is estimated to be HIV-HCV co-infected [19] and these individuals are a vulnerable subset of this population. While cART has made HIV infection a chronic manageable condition, comorbidities such as liver disease and liver-related mortality are increasing [20]. A recent study estimated that allcause mortality in a Canadian population of co-infected individuals is 12 times higher than that of the overall Canadian population of similar sex and age; liver disease and drug overdose were among the most frequent causes of death [21].

Research comparing HIV mono-infected and co-infected individuals has consistently highlighted the cumulative vulnerabilities experienced in co-infection, many of which may act on one's ability to acquire food. Studies suggest that the sociodemographic (e.g., unstable housing), socioeconomic (e.g., unemployment), behavioral (e.g., injection drug use), and clinical (e.g., depressive symptoms) characteristics of this subpopulation lead to more fatigue, poorer quality of life, and less social support [22, 23]. It has also been shown that co-infected individuals experience more co-morbid conditions [24] and a Canadian study has documented differences in the social determinants of health between mono-infected and co-infected individuals [25]. Despite HIV-HCV co-infected individuals being an important HIV-positive subpopulation, where we hypothesize that FI may be highly prevalent and more severe, this issue has not been studied in a population of HIV-positive individuals known to be co-infected with $\mathrm{HCV}$.

This exploratory study was conducted to identify sociodemographic, socioeconomic, behavioral, and clinical factors associated with FI in a population of HIV-HCV coinfected individuals in Canada. While this hypothesisgenerating work provides insights into factors that may be targeted for potential intervention, the primary objective was to suggest important variables for consideration in future hypothesis-confirming analyses.

\section{Methods}

\section{Study Design and Population}

The Canadian Co-infection Cohort (CCC) is a prospective multi-centre study recruiting $\mathrm{HIV}-\mathrm{HCV}$ co-infected individuals who receive care from urban and semi-urban HIV clinics in Canada [26]. This study, initiated in 2003, follows participants in 6 Canadian provinces (British Columbia, Ontario, Quebec, Alberta, Saskatchewan, and Nova Scotia); participating health centres routinely screen all HIV-positive individuals for $\mathrm{HCV}$ infection. The eligibility criteria for the CCC are: older than 16 years of age, documented HIV infection (HIV seropositive by ELISA with Western blot confirmation), and evidence of $\mathrm{HCV}$ infection (HCV RNA positive and/or HCV seropositive by ELISA with RIBA II, EIA confirmation) [26]. All eligible individuals are invited to participate in the CCC where longitudinal data collection (questionnaires and blood samples) occurs every 6 months.

In 2012, a mixed methods Food Security and HIV-HCV Co-infection Study (FS Study) was initiated within the 
$\mathrm{CCC}$ and data collection related to FI was integrated into CCC study visits (i.e., an additional questionnaire was administered by a study coordinator during routine clinical visits). All CCC participants were invited to enroll in the FS Study. Between November 2012 and June 2014, 525 coinfected participants completed at least one FI assessment at 15 study sites, with 274 completing a second assessment, 21 a third, and 1 a fourth; these individuals make up our study sample. Non-participation, formal withdrawals, deaths, and losses to follow-up in the FS Study were recorded at each site. The FS Study and CCC were approved by the research ethics boards of all participating institutions [26] and the community advisory committee of the CIHR Canadian HIV Trials Network.

\section{Measures}

\section{Food Insecurity Assessment}

At each study visit, FI in the past 6 months was measured using the 10-item adult scale of the HFSSM [27]. Modification of the HFSSM to a shorter reference period, as done in this study (i.e., from 12 to 6 months), has been justified in previous literature [28]. The HFSSM focuses on selfreports of uncertain, insufficient or inadequate food access, availability and utilization due to limited financial resources, and the compromised eating patterns and food consumption that may result.

Health Canada categorizes FI as food secure (none, or one, indication of difficulty with income-related food access), moderate FI (indication of compromise in quality and/or quantity of food consumed), and severe FI (multiple indications of reduced food intake and disrupted eating patterns) [27]. The HFSSM was adapted from the Current Population Survey Food Security Supplement that has been administered in the United States since 1995 [28]; the HFSSM differs primarily in the FI category labels and the thresholds for defining severity categories [27]. Health Canada categorizes FI according to the number of affirmative responses on the 10-item HFSSM [27]. For example, one item asks: "you and other household members worried that food would run out before you got money to buy more. Was that often true, sometimes true, or never true?" The affirmative responses "often true" and "sometimes true" are treated equally. While previous work acknowledges that the tool does not differentiate frequency-of-occurrence information, it has been shown that either response is indicative of FI [6]. Each of the 10 items used to measure FI and the baseline frequency of responses are described in Table S1 (Supplementary Material). All 10 items, regardless of the severity of FI, are treated equally, where it has been shown that more severe items (i.e., items 6-10) are less frequently affirmed than less severe items [29]. To assess the internal consistency of the HFSSM over time, Cronbach's alpha were calculated at each study visit.

As per Health Canada criteria, participants with $0-1,2-5$, or $\geq 6$ affirmative responses were classified respectively as being food secure, moderately food insecure, or severely food insecure [27]. For regression modeling, we defined the outcome as a binary indicator of FI (food secure vs. food insecure), where participants with $\geq 2$ affirmative responses were classified as food insecure (collapsing moderate and severe FI into a single category) in the past 6 months.

\section{Covariates Describing the Study Sample}

In addition to the covariates evaluated for their association with FI, the following factors (some of which are possible consequences of FI and therefore not included in regression models) were used to describe the study sample at baseline (Table 1). Behavioral factors included: use of food assistance (yes vs. no) and doing the following for food: borrowing money, stealing, begging, selling or pawning personal or household items, delaying paying rent or bills (yes vs. no). Clinical factors included: HIV and HCV infection duration (years), CD4 count (cells $/ \mu \mathrm{L}$ ), HIV RNA $\left(<50\right.$ copies $/ \mathrm{mL}$; yes vs. no), body mass index $\left(\mathrm{kg} / \mathrm{m}^{2}\right)$, diagnoses of end-stage liver disease or AIDS-defining illnesses (yes vs. no), HCV treatment naïve (yes vs. no), missing cART doses in the past 4 days (yes vs. no), and healthcare usage (emergency room visit or hospitalization; yes vs. no).

\section{Covariates Evaluated for Their Association with Food Insecurity}

Informed by existing evidence regarding FI in HIV-positive populations in Canada and the United States [15-17], various sociodemographic, socioeconomic, behavioral, and clinical factors were evaluated for their potential association with FI (Table 2). Sociodemographic factors included: age (years), sex (male vs. female), born in Canada (yes vs. no), province of study enrolment (Ontario, Quebec, Other [Alberta, Saskatchewan, Nova Scotia] vs. British Columbia), Aboriginal (First Nations, Inuit, or Métis vs. Other), sexual orientation (heterosexual vs. homosexual or bisexual), living alone (yes vs. no), without a fixed address (yes vs. no), recent changes in housing situation (yes vs. no), and recent incarceration (yes vs. no). Socioeconomic factors included: employment (yes vs. no), average personal monthly income (including all sources, before taxes and deductions; \$ CAD: Canadian dollars), and more than high school education (yes vs. no). Behavioral factors included: substance use (i.e., marijuana, cigarettes, alcohol, injection drugs; yes vs. no), trading away food for: tobacco, personal or household items, drugs, alcohol, sex, a place to stay (yes 
Table 1 Baseline descriptive characteristics and factors evaluated for their association with food insecurity in 525 HIV-HCV co-infected study participants between November 2012 and June 2014, Canada

\begin{tabular}{|c|c|c|c|c|c|c|}
\hline \multirow[t]{2}{*}{ Characteristics } & \multirow{2}{*}{$\begin{array}{c}\text { Total } \\
(\mathrm{N}=525)\end{array}$} & \multirow{2}{*}{$\begin{array}{l}\text { Food secure } \\
(\mathrm{N}=213)\end{array}$} & \multicolumn{3}{|c|}{ Food insecure $(\mathrm{N}=312)$} & \multirow{2}{*}{$\begin{array}{l}\text { Missing } \\
\text { obs. }^{\text {a }}\end{array}$} \\
\hline & & & $\begin{array}{l}\text { Moderate } \\
(\mathrm{N}=129)\end{array}$ & $\begin{array}{c}\text { Severe } \\
(\mathrm{N}=183)\end{array}$ & $\begin{array}{c}\text { Total } \\
(\mathrm{N}=312)\end{array}$ & \\
\hline Sociodemographic & \multicolumn{6}{|c|}{ Values are number of participants $(\%)$ or median $(\mathrm{Q} 1, \mathrm{Q} 3)$} \\
\hline Age (years) & $49.1(43.5,54.1)$ & $50.4(45.1,55.2)$ & $48.1(41.1,52.9)$ & $48.5(43.7,53.5)$ & $48.4(42.7,53.5)$ & 0 \\
\hline Male & $390(74 \%)$ & $170(80 \%)$ & $90(70 \%)$ & $130(71 \%)$ & $220(71 \%)$ & 0 \\
\hline Born in Canada & $395(75 \%)$ & $162(76 \%)$ & $97(75 \%)$ & $136(74 \%)$ & $233(75 \%)$ & 88 \\
\hline Province of enrolment & - & - & - & - & - & - \\
\hline British Columbia & $171(33 \%)$ & $50(24 \%)$ & $50(39 \%)$ & $71(39 \%)$ & $121(39 \%)$ & 0 \\
\hline Ontario & $95(18 \%)$ & $41(19 \%)$ & $27(21 \%)$ & $27(15 \%)$ & $54(17 \%)$ & 0 \\
\hline Quebec & $248(47 \%)$ & $115(54 \%)$ & $48(37 \%)$ & $85(46 \%)$ & $133(43 \%)$ & 0 \\
\hline Other $^{\mathrm{b}}$ & $11(2 \%)$ & $7(3 \%)$ & $4(3 \%)$ & 0 & $4(1 \%)$ & 0 \\
\hline Aboriginal & $78(15 \%)$ & $24(11 \%)$ & $28(22 \%)$ & $26(14 \%)$ & $54(17 \%)$ & 9 \\
\hline Heterosexual & $364(69 \%)$ & $138(65 \%)$ & $96(74 \%)$ & $130(71 \%)$ & $226(72 \%)$ & 0 \\
\hline Living alone $\mathrm{e}^{\mathrm{c}}$ & $274(52 \%)$ & $103(48 \%)$ & $74(57 \%)$ & $97(53 \%)$ & $171(55 \%)$ & 0 \\
\hline Without a fixed address ${ }^{c}$ & $23(4 \%)$ & $3(1 \%)$ & $4(3 \%)$ & $16(9 \%)$ & $20(6 \%)$ & 0 \\
\hline $\begin{array}{l}\text { Recent changes in housing } \\
\text { situation }^{\mathrm{d}}\end{array}$ & $140(27 \%)$ & $46(22 \%)$ & $32(25 \%)$ & $62(34 \%)$ & $94(30 \%)$ & 0 \\
\hline Recent incarceration ${ }^{\mathrm{d}}$ & $55(10 \%)$ & $15(7 \%)$ & $14(11 \%)$ & $26(14 \%)$ & $40(13 \%)$ & 0 \\
\hline \multicolumn{7}{|l|}{ Socioeconomic } \\
\hline Employment $^{\mathrm{c}}$ & $97(19 \%)$ & $64(30 \%)$ & $21(16 \%)$ & $12(7 \%)$ & $33(11 \%)$ & 0 \\
\hline $\begin{array}{l}\text { Average personal monthly } \\
\text { income }(\$ C A D)^{\mathrm{d}}\end{array}$ & $1015(918,1400)$ & $1111(934,2500)$ & $1100(918,1300)$ & $966(897,1100)$ & $1000(916,1200)$ & 3 \\
\hline $\begin{array}{l}\text { More than high school } \\
\text { education }\end{array}$ & $132(25 \%)$ & $75(35 \%)$ & $21(16 \%)$ & $36(20 \%)$ & $57(18 \%)$ & 0 \\
\hline \multicolumn{7}{|l|}{ Behavioral } \\
\hline Recent injection drug use ${ }^{\mathrm{d}}$ & $180(34 \%)$ & $44(21 \%)$ & $48(37 \%)$ & $88(48 \%)$ & $136(44 \%)$ & 0 \\
\hline Marijuana use ${ }^{c}$ & $287(55 \%)$ & $94(44 \%)$ & $68(53 \%)$ & $125(68 \%)$ & $193(62 \%)$ & 0 \\
\hline Cigarette use $\mathrm{e}^{\mathrm{c}}$ & $372(71 \%)$ & $132(62 \%)$ & $96(74 \%)$ & $144(79 \%)$ & $240(77 \%)$ & 46 \\
\hline Alcohol use $\mathrm{c}^{\mathrm{c}}$ & $306(58 \%)$ & $115(54 \%)$ & $74(57 \%)$ & $117(64 \%)$ & $191(61 \%)$ & 45 \\
\hline$\geq 5$ alcoholic drinks per day ${ }^{\mathrm{c}}$ & $96(18 \%)$ & $21(10 \%)$ & $26(20 \%)$ & $49(27 \%)$ & $75(24 \%)$ & 48 \\
\hline Trading away food ${ }^{\mathrm{d}, \mathrm{e}}$ & $75(14 \%)$ & $6(3 \%)$ & $18(14 \%)$ & $51(28 \%)$ & $69(22 \%)$ & 0 \\
\hline $\begin{array}{l}\text { Use of food assistance (in the } \\
\text { past month) }\end{array}$ & $346(66 \%)$ & $82(38 \%)$ & $109(84 \%)$ & $155(85 \%)$ & $264(85 \%)$ & 0 \\
\hline Doing the following for food ${ }^{\mathrm{d}}$ & - & - & - & - & - & - \\
\hline Borrowing money & $224(43 \%)$ & $25(12 \%)$ & $65(50 \%)$ & $134(73 \%)$ & $199(64 \%)$ & 0 \\
\hline Going through garbage & $25(5 \%)$ & $1(<1 \%)$ & $5(4 \%)$ & $19(10 \%)$ & $24(8 \%)$ & 0 \\
\hline Stealing & $64(12 \%)$ & $4(2 \%)$ & $13(10 \%)$ & $47(26 \%)$ & $60(19 \%)$ & 0 \\
\hline Begging & $60(11 \%)$ & $3(1 \%)$ & $9(7 \%)$ & $48(26 \%)$ & $57(18 \%)$ & 0 \\
\hline Selling or trading items & $104(20 \%)$ & $5(2 \%)$ & $23(18 \%)$ & $76(42 \%)$ & $99(32 \%)$ & 0 \\
\hline Having sex for food & $22(4 \%)$ & $2(1 \%)$ & $4(3 \%)$ & $16(9 \%)$ & $20(6 \%)$ & 0 \\
\hline Trading substances & $52(10 \%)$ & $3(1 \%)$ & $11(9 \%)$ & $38(21 \%)$ & $49(16 \%)$ & 0 \\
\hline Delaying payments & $115(22 \%)$ & $7(3 \%)$ & $22(17 \%)$ & $86(47 \%)$ & $108(35 \%)$ & 0 \\
\hline \multicolumn{7}{|l|}{ Clinical } \\
\hline HIV infection duration (years) & $15.5(10.3,20.7)$ & $16.7(10.4,22.3)$ & $14.5(9.9,19.9)$ & $15.2(10.3,19.3)$ & $15.0(10.3,19.4)$ & 23 \\
\hline HCV infection duration (years) & $23.1(15.7,30.7)$ & $22.9(11.2,30.1)$ & $22.0(16.9,31.2)$ & $24.0(17.2,30.7)$ & $23.3(17.1,31.0)$ & 0 \\
\hline CD4 count $($ cells $/ \mu \mathrm{L})$ & $460(310,680)$ & $493.5(320,705)$ & $466(314,692)$ & $432(300,620)$ & $446(300,632)$ & 7 \\
\hline HIV RNA ( $<50$ copies/mL) & $412(78 \%)$ & $172(81 \%)$ & $105(81 \%)$ & $135(74 \%)$ & $240(77 \%)$ & 16 \\
\hline Body mass index $\left(\mathrm{kg} / \mathrm{m}^{2}\right)$ & $23.7(21.2,27.2)$ & $24.1(21.4,27.6)$ & $24.2(22.1,27.4)$ & $23.3(20.7,26.6)$ & $23.6(21.1,27.0)$ & 67 \\
\hline
\end{tabular}


Table 1 continued

\begin{tabular}{|c|c|c|c|c|c|c|}
\hline \multirow[t]{2}{*}{ Characteristics } & \multirow{2}{*}{$\begin{array}{c}\text { Total } \\
(\mathrm{N}=525)\end{array}$} & \multirow{2}{*}{$\begin{array}{l}\text { Food secure } \\
(\mathrm{N}=213)\end{array}$} & \multicolumn{3}{|c|}{ Food insecure $(\mathrm{N}=312)$} & \multirow{2}{*}{$\begin{array}{l}\text { Missing } \\
\text { obs. }^{\text {a }}\end{array}$} \\
\hline & & & $\begin{array}{l}\text { Moderate } \\
(\mathrm{N}=129)\end{array}$ & $\begin{array}{c}\text { Severe } \\
(\mathrm{N}=183)\end{array}$ & $\begin{array}{c}\text { Total } \\
(\mathrm{N}=312)\end{array}$ & \\
\hline $\begin{array}{l}\text { End-stage liver disease } \\
\text { diagnosis }^{\mathrm{f}}\end{array}$ & $82(16 \%)$ & $39(18 \%)$ & $13(10 \%)$ & $30(16 \%)$ & $43(14 \%)$ & 0 \\
\hline $\begin{array}{l}\text { AIDS-defining illness } \\
\text { diagnosis }^{f}\end{array}$ & $146(28 \%)$ & $66(31 \%)$ & $33(26 \%)$ & $47(26 \%)$ & $80(26 \%)$ & 0 \\
\hline $\mathrm{HCV}$ treatment naïve ${ }^{\mathrm{f}}$ & $331(63 \%)$ & $113(53 \%)$ & $93(72 \%)$ & $125(68 \%)$ & $218(70 \%)$ & 0 \\
\hline Taking $\mathrm{cART}^{\mathrm{c}}$ & $484(92 \%)$ & $201(94 \%)$ & $123(95 \%)$ & $160(87 \%)$ & $283(91 \%)$ & 0 \\
\hline $\begin{array}{l}\text { Missing cART doses (in the } \\
\text { past } 4 \text { days) }\end{array}$ & $110(21 \%)$ & $31(15 \%)$ & $28(22 \%)$ & $51(28 \%)$ & $79(25 \%)$ & 0 \\
\hline $\begin{array}{l}\text { Self-described health state- } \\
\text { visual analogue scale } \\
(0-100)^{\mathrm{c}}\end{array}$ & $70(55,80)$ & $75(60,85)$ & $70(50,80)$ & $65(50,75)$ & $70(50,80)$ & 4 \\
\hline Therapy for drug addiction ${ }^{\mathrm{d}}$ & $97(19 \%)$ & $27(13 \%)$ & $21(16 \%)$ & $49(27 \%)$ & $70(22 \%)$ & 29 \\
\hline $\begin{array}{l}\text { Recent depressive symptoms } \\
\text { (CES-D-10) (in the past } \\
\text { week) }\end{array}$ & $276(53 \%)$ & $76(36 \%)$ & $67(52 \%)$ & $133(73 \%)$ & $200(64 \%)$ & 13 \\
\hline Unmet healthcare needs ${ }^{\mathrm{d}}$ & $95(18 \%)$ & $19(9 \%)$ & $26(20 \%)$ & $50(27 \%)$ & $76(24 \%)$ & 0 \\
\hline Healthcare usage $^{\mathrm{d}}$ & - & - & - & - & - & - \\
\hline Emergency room visit & $144(27 \%)$ & $48(23 \%)$ & $40(31 \%)$ & $56(31 \%)$ & $96(31 \%)$ & 0 \\
\hline Hospitalization & $75(14 \%)$ & $23(11 \%)$ & $20(16 \%)$ & $32(17 \%)$ & $52(17 \%)$ & 0 \\
\hline
\end{tabular}

${ }^{a}$ Number of observations missing at the baseline assessment

b Provinces of Alberta, Saskatchewan, and Nova Scotia

${ }^{c}$ Reference period: currently

${ }^{\mathrm{d}}$ Reference period: in the past 6 months

e Trading away food for: tobacco, personal or household items, drugs, alcohol, sex, a place to stay

${ }^{\mathrm{f}}$ Reference period: lifetime

vs. no). Clinical factors included: taking cART (yes vs. no), self-described health state (visual analogue scale, $0=$ worst imaginable health state to $100=$ best imaginable health state), recent therapy for drug addiction (yes vs. no), experiences of recent depressive symptoms (measured using the 10-item Center for Epidemiological Studies Depression Scale: CES-D-10, and defined by a score of $\geq 10$ on the scale; yes vs. no) [30], and self-reports of unmet healthcare needs (yes vs. no).

The reference periods for each measurement are indicated in the table footnotes. The following factors were ascertained by research nurses/coordinators at study sites: CD4 count (cells/ $\mu \mathrm{L})$, HIV RNA ( $<50$ copies $/ \mathrm{mL}$ ), body mass index $\left(\mathrm{kg} / \mathrm{m}^{2}\right)$, diagnoses of end-stage liver disease or AIDS-defining illnesses, HCV treatment naïve, and taking cART. All other factors were self-reported by participants.

\section{Data Analyses}

Summary statistics were used to describe the study sample at baseline and frequencies were stratified by FI and FI severity: food secure, moderate FI, and severe FI. Multiple imputation by chained equations were used to impute missing observations across all study visits using 20 imputations and 25 iterations, with continuous variables imputed using predictive mean matching and logistic regression (including polytomous regression) used for categorical variables. To account for repeated measurements on participants over time, generalized estimating equations (GEE) were used to estimate the marginal parameters of univariate and multivariate logistic regression models with a working autoregressive correlation structure.

The dependent variable was a binary indicator of FI (food secure vs. food insecure), collapsing moderate and severe FI into a single category. Factors evaluated for their association with FI were included in the logistic models as independent variables. Given the exploratory nature of the study, all factors significant at the liberal two-tailed $p<0.1$ in univariate models were simultaneously included in the multivariate model; no model reduction was performed. Statistical significance in the multivariate model was defined as a two-tailed $p<0.05$. All models were fit to each of the 20 imputed datasets, where the coefficients and 
Table 2 Univariate and multivariate logistic regression models of factors associated with food insecurity in 525 HIV-HCV co-infected study participants between November 2012 and June 2014, Canada

\begin{tabular}{|c|c|c|c|c|}
\hline & $\begin{array}{l}\text { Univariate OR } \\
(95 \% \mathrm{CI})^{\mathrm{a}}\end{array}$ & $p$ value $^{\mathrm{b}}$ & $\begin{array}{l}\text { Multivariate aOR } \\
\quad(95 \% \mathrm{CI})\end{array}$ & $p$ value \\
\hline \multicolumn{5}{|l|}{ Sociodemographic } \\
\hline Intercept & - & - & $4.78(0.98,23.41)$ & 0.054 \\
\hline Age: per 5-year increase & $0.85(0.77,0.94)$ & $<0.001$ & $0.90(0.81,1.00)$ & 0.057 \\
\hline Male & $1.58(1.07,2.31)$ & 0.020 & $1.26(0.78,2.04)$ & 0.343 \\
\hline Born in Canada & $1.09(0.62,1.91)$ & 0.764 & - & - \\
\hline Province of enrolment & - & - & - & - \\
\hline British Columbia & Ref. & Ref. & Ref. & Ref. \\
\hline Ontario & $0.50(0.31,0.81)$ & 0.005 & $0.74(0.43,1.27)$ & 0.275 \\
\hline Quebec & $0.45(0.30,0.65)$ & $<0.001$ & $0.42(0.27,0.67)$ & $<0.001^{*}$ \\
\hline Other $^{\mathrm{c}}$ & $0.24(0.07,0.84)$ & 0.025 & $0.49(0.14,1.73)$ & 0.265 \\
\hline Aboriginal & $1.75(1.08,2.82)$ & 0.022 & $1.12(0.58,2.13)$ & 0.759 \\
\hline Heterosexual & $1.52(1.07,2.16)$ & 0.019 & $1.12(0.73,1.70)$ & 0.605 \\
\hline Living alone $^{\mathrm{d}}$ & $1.44(1.09,1.89)$ & 0.010 & $1.31(0.92,1.87)$ & 0.128 \\
\hline Without a fixed address ${ }^{\mathrm{d}}$ & $2.19(1.16,4.14)$ & 0.016 & $1.19(0.50,2.84)$ & 0.689 \\
\hline Recent changes in housing situation ${ }^{\mathrm{e}}$ & $1.44(1.06,1.95)$ & 0.021 & $1.11(0.73,1.68)$ & 0.635 \\
\hline Recent incarceration ${ }^{\mathrm{e}}$ & $1.96(1.14,3.36)$ & 0.015 & $1.11(0.59,2.08)$ & 0.749 \\
\hline \multicolumn{5}{|l|}{ Socioeconomic } \\
\hline Employment $^{\mathrm{d}}$ & $0.34(0.24,0.49)$ & $<0.001$ & $0.55(0.35,0.87)$ & $0.010^{*}$ \\
\hline Average personal monthly income (\$CAD): per $\$ 100$ increase $^{\mathrm{e}}$ & $0.96(0.93,0.99)$ & 0.012 & $0.98(0.97,0.99)$ & $0.001^{*}$ \\
\hline More than high school education & $0.45(0.30,0.66)$ & $<0.001$ & $0.72(0.45,1.13)$ & 0.155 \\
\hline \multicolumn{5}{|l|}{ Behavioral } \\
\hline Recent injection drug use ${ }^{\mathrm{e}}$ & $2.79(2.02,3.85)$ & $<0.001$ & $1.98(1.33,2.96)$ & $<0.001^{*}$ \\
\hline Marijuana use $^{\mathrm{d}}$ & $1.82(1.37,2.42)$ & $<0.001$ & $1.41(0.99,2.01)$ & 0.060 \\
\hline Cigarette use $^{\mathrm{d}}$ & $1.67(1.18,2.35)$ & 0.004 & $0.98(0.65,1.50)$ & 0.940 \\
\hline Alcohol use ${ }^{\mathrm{d}}$ & $1.28(0.97,1.67)$ & 0.077 & $1.21(0.84,1.75)$ & 0.301 \\
\hline$\geq 5$ alcoholic drinks per day ${ }^{\mathrm{d}}$ & $1.55(1.06,2.25)$ & 0.023 & $1.21(0.75,1.94)$ & 0.433 \\
\hline Trading away food ${ }^{\mathrm{e}, \mathrm{f}}$ & $5.99(3.53,10.16)$ & $<0.001$ & $5.23(2.53,10.81)$ & $<0.001^{*}$ \\
\hline \multicolumn{5}{|l|}{ Clinical } \\
\hline Taking cART ${ }^{\mathrm{d}}$ & $0.52(0.31,0.88)$ & 0.015 & $0.68(0.36,1.29)$ & 0.237 \\
\hline $\begin{array}{l}\text { Self-described health state-visual analogue scale }(0-100) \text { : } \\
\text { per 5-point increase }\end{array}$ & $0.93(0.89,0.96)$ & $<0.001$ & $0.98(0.94,1.02)$ & 0.242 \\
\hline Therapy for drug addiction ${ }^{\mathrm{e}}$ & $1.16(0.79,1.71)$ & 0.452 & - & - \\
\hline Recent depressive symptoms (CES-D-10) (in the past week) & $2.78(2.06,3.74)$ & $<0.001$ & $2.11(1.48,3.01)$ & $<0.001^{*}$ \\
\hline Unmet healthcare needs ${ }^{\mathrm{e}}$ & $2.25(1.55,3.26)$ & $<0.001$ & $1.55(0.93,2.57)$ & 0.091 \\
\hline
\end{tabular}

${ }^{\text {a }}$ OR odds ratios, $95 \%$ CI confidence intervals, and $a O R$ adjusted ORs estimated from logistic regression models (outcome: food secure vs. food insecure) using GEE

${ }^{\mathrm{b}}$ Factors $p<0.1$ in univariate models were included in the multivariate model

c Provinces of Alberta, Saskatchewan, and Nova Scotia

${ }^{\mathrm{d}}$ Reference period: currently

e Reference period: in the past 6 months

f Trading away food for: tobacco, personal or household items, drugs, alcohol, sex, a place to stay

$* p<0.05$ 
variance estimates were subsequently combined using Rubin's method to account for between-imputation variability [31]. All data analyses were performed using $R$ (Version 3.2.0-R Foundation for Statistical Computing).

\section{Results}

Due to the number of participants with only a single baseline assessment $(\mathrm{N}=251$ of $525,48 \%)$, the mean followup time in the FS Study was 0.20 years (IQR: 0.0, 0.47). Between November 2012 and June 2014, 9 participants refused to enroll in the study, 0 withdrew, 14 died, and 0 participants were lost to follow-up (based on the CCC definition for loss to follow-up, missing 3 consecutive study visits over 18 months). The internal consistency of the 10-item HFSSM was acceptable in this study sample [32], where Cronbach's alpha at each study visit exceeded 0.90 .

Table 1 indicates that the majority of the participants were food insecure $(\mathrm{N}=312,59 \%) ; 41$ and $59 \%$ of these participants experienced moderate and severe FI, respectively. The median age of the study sample was 49.1 years (IQR: $43.5,54.1$ ), $74 \%$ were male, and $47 \%$ of participants were enrolled at a Quebec study site. A small proportion of the sample did not have a fixed address $(4 \%)$. Nineteen percent of participants were employed, and the average personal monthly income was \$1015 CAD (IQR: $918,1400)$. The majority of the participants engaged in cigarette $(71 \%)$, alcohol $(58 \%)$, and marijuana (55\%) use, and recently experienced depressive symptoms (53\%). Also, $92 \%$ of participants were taking cART for HIV and $34 \%$ reported use of injection drugs in the past 6 months. Borrowing money to buy food was a common strategy used by food insecure participants. Lastly, a notable proportion of participants experiencing FI traded away food $(22 \%)$, most commonly for tobacco, personal or household items, or drugs.

Table 2 indicates that all but two factors (i.e., whether or not the participant was born in Canada and whether or not the participant had recently been in therapy for drug addiction) were significantly associated with FI in univariate logistic regressions. In the multivariate model, protective factors that remained significantly associated with FI $(p<0.05)$ included: enrolment at a Quebec study site (aOR: 0.42, $95 \%$ CI: 0.27, 0.67), employment (aOR: $0.55,95 \%$ CI: $0.35,0.87)$, and average personal monthly income (aOR per \$100 CAD increase: 0.98, $95 \%$ CI: 0.97 , 0.99). Significant risk factors for FI included: recent injection drug use (aOR: 1.98, $95 \%$ CI: 1.33, 2.96), trading away food (aOR: $5.23,95 \%$ CI: $2.53,10.81$ ), and recent experiences of depressive symptoms (aOR: $2.11,95 \% \mathrm{CI}$ : $1.48,3.01)$.

\section{Discussion}

FI is common (59 \%) in this co-infected population and the majority of food insecure participants experienced severe FI, indicating reduced food intake and disrupted eating patterns [27]. In previous evaluations of HIV-positive populations in British Columbia and Ontario, approximately $70 \%$ of participants were food insecure [1, 7]; FI severity was not explored in these studies. However, these single-province prevalence estimates may not be directly comparable as our interprovincial study uses a different FI assessment tool than the British Columba study.

Geographically, most Canadian FI-related research involving HIV-positive populations has been conducted in British Columbia [1, 4]. In our study, important differences in the proportions of individuals experiencing FI were noted across provinces, where the baseline proportions of participants experiencing FI in British Columbia, Ontario, and Quebec were 71, 57, and $54 \%$, respectively. Therefore, the prevalence of FI in our co-infected study sample in British Columbia is similar to that documented in an HIV-positive population in this province $(71 \%)$ [1]. However, given our use of interprovincial data (approximately half of the study sample is from Quebec; FI prevalence of $54 \%$ ); the estimated prevalence of FI (59\%) is reduced compared to the British Columbia study. Additionally, this study used a different FI assessment tool (Radimer/Cornell questionnaire vs. HFSSM) with different thresholds to define FI [29]. Lastly, as described, an unknown proportion of HIV-positive participants in the British Columbia study may have been co-infected with $\mathrm{HCV}$, making direct comparisons of FI prevalence difficult. Regardless of these differences, these prevalence estimates consistently indicate high levels of deprivation in terms of food access among these populations; they are markedly higher than the annual estimate of $8 \%$ for Canadian adults [8].

As described, co-infected populations experience less favourable sociodemographic, socioeconomic, behavioral, and clinical conditions leading to more fatigue, poorer quality of life, less social support, and more co-morbid conditions [23-25]. These cumulative vulnerabilities may modify the effects of risk factors for FI in the co-infection context. For example, recent experiences of depressive symptoms, identified as a significant risk factor in both our study sample as well as in HIV-positive populations, may have a stronger effect in co-infected individuals given cumulative vulnerabilities (e.g., less social support, more substance use, and other co-morbidities). In order to investigate this hypothesis, one could compare the effects estimated in our study to those found in studies of HIV mono-infected populations in similar settings. However, 
given that previous studies in Canada do not report on the presence of $\mathrm{HCV}$ co-infection, such comparisons are challenging. Alternatively, a quantitative assessment of this hypothesis would require a study population containing both HIV mono-infected and HIV-HCV co-infected individuals, and where co-infection status is known. In such a scenario, effect measure modification could be assessed in regression modeling by creating an interaction term between an indicator for being co-infected and the risk factor(s) of interest. This is not possible in our study as all participants are co-infected with HCV. Therefore, we recommend that future research report on the presence of HCV co-infection and explore whether the cumulative vulnerabilities experienced in co-infection modify the effects of risk factors for FI.

Regarding protective factors in the multivariate model, Quebec participants were less likely to experience FI (using British Columbia as the referent province) after adjustment for many sociodemographic, socioeconomic, behavioral, and clinical factors. However, the underlying reasons for provincial differences in FI in our study, including differences in the severity of FI, remain to be explained. Qualitative interview data on FI, collected among FS Study participants in Vancouver, Toronto, and Montreal may provide useful insights. Also, future analyses will use additional data from the FS Study to examine the distributions of important contextual factors (e.g., social support services) across provinces and describe their effects on FI in these distinct geographical regions.

Recognizing that direct comparisons with past studies are difficult, many of the other observed associations are consistent with previous studies in HIV-positive populations [1-4]. Both greater average personal monthly income and current employment were significantly and negatively associated with FI. These associations were expected given the HFSSMs focus on inadequate food access due to limited financial resources [27]. Regarding risk factors for FI, $34 \%$ of participants reported injecting drugs in the past 6 months and recent injection drug use was significantly associated with FI. Illicit drug use (including but not limited to injection drug use) has previously been described as a risk factor for FI in HIV-positive populations [1-4]. Illicit drug use is believed to act on FI through behavioral and environmental pathways [16] and may contribute to FI by further disrupting food intake patterns, resulting in the consumption of foods that are inadequate in quantity and/or quality [33, 34]. Illicit drug using environments also contribute to FI by imposing social, economic, physical, and policy barriers to food access and availability [35-39]. As suggested by others [1-4], our work also indicates that FI is an associated harm of injection drug use. Therefore, engagement of co-infected individuals in substance use treatments and harm reduction programs (e.g., opioid substitution programs and other clinical services used by individuals who inject drugs) may act to mitigate FI in this population. However, it should be noted that the unadjusted effect of recent drug addiction therapy on FI was nonsignificant. This contradiction may be explained by the fact that this estimate reflects the effect of being in recent therapy (in the past 6 months). It is possible that those in recent therapy have yet to experience the benefits of such programs. Also, if the individuals engaging in therapy are those with the highest frequency and duration of substance use, this unadjusted effect is likely to be confounded by such factors. Lastly, addiction therapy is only one treatment program available for individuals who use drugs. We suspect that in addition to addiction therapy, other clinical services and harm reduction programs are necessary for reducing FI. Future hypothesis-confirming research will use effect decomposition and mediation analyses, where modeling is guided by directed acyclic graphs, to better understand the pathways underlying injection drug use, drug addiction, and FI.

With the exception of injection drug use, none of the other substance use variables (use of marijuana, cigarettes, or alcohol) remained significant in the adjusted model. This may be partially explained by a trajectory of drug use [40] wherein injection often occurs after an individual builds a tolerance to, and becomes dependent on, a highly addictive substance (e.g., opiates, cocaine) [41]. Therefore, while the instability of injecting drugs may significantly affect an individual's FI [42], this may be less so for other substances, given differences in mechanisms of action, effects, and potential harms. However, the non-significant effects for these substances may be due to different reference periods for use and no information on the frequency and duration of use. These are important considerations as a recent study in an HIV-positive population in the United States found that those who use tobacco and alcohol may use up to one-quarter of their financial resources on these substances [43]. As shown in Table 1, the majority of food insecure participants used marijuana, cigarettes, and also consumed alcohol. Therefore, in a co-infected population where substance use is common, sufficient details regarding the use of all substances (including illicit use by noninjection), as well as how priorities are established in the context of limited resources, are needed to understand their roles in contributing to $\mathrm{FI}$.

Competing needs and demands on financial resources are an issue in this HIV-HCV co-infected population. The largest effect on FI was observed for trading food, where trading food for tobacco, personal or household items, or drugs were the most common practices. Research has documented that even in situations of hunger, individuals may use food as a commodity to meet other needs. In studies of street-involved youth and inner city drug-using 
women, food is treated as a coveted resource that can be used to gain favour, including drugs [44-46]. A possible explanation is that food can be obtained for free from distribution sites. Therefore, in the context of substance use and addiction, food may be forgone or traded to meet other needs, potentially leading to FI.

Similarly to the study of FI in an HIV-positive population in British Columbia [1], our work demonstrates that recent experiences of depressive symptoms are a significant risk factor for FI. Different mechanisms have been proposed, including the role of neurovegetative symptoms: loss of interest, appetite change, psychomotor agitation or retardation, fatigue, and a diminished ability to think or concentrate [47]. Alternatively, experiencing FI implies uncertainty about food access [27], possibly inciting coping strategies (e.g., obtaining food in socially unacceptable ways) that may lead to stress and depression in the long term $[48,49]$. Although directionality is unclear, the experience of depressive symptoms is linked with the experience of FI. As such, FI in co-infected individuals may be mitigated through the use of mental health services that identify and treat depressive symptoms in this population [1, 16]. However, additional mechanism-oriented modeling (informed by directed acyclic graphs) is needed to further understand this relationship. By using lagged covariates, such a study could establish directionality of the depressive symptoms-FI relationship, and explore mediating variables in such a pathway.

Recognizing the exploratory nature of this work, we provide insights into factors that may be targeted for potential intervention. Specifically, given the high levels of injection drug use in co-infected populations [26, 50], substance use treatments and harm reduction programs could potentially reduce FI. A similar potential may exist for mental health services based on the frequent occurrence of depressive symptoms in co-infected individuals [22, 23, 25]. Further research is needed to identify whether the integration of FI screening and FI prevention into these programs is effective at reducing FI and related adverse health outcomes.

\section{Strengths and Limitations}

To our knowledge, our interprovincial study is the first to estimate the prevalence of FI and describe factors associated with FI in an HIV-HCV co-infected population in Canada. Through the use of a validated measure of FI, this work contributes to an evidence base describing FI among a vulnerable subset of the HIV-positive population [51]. It also draws upon longitudinal data from both the FS Study and the $\mathrm{CCC}$, allowing us to explore and describe associations between a variety of factors and FI. Additionally, given minimal non-participation, withdrawals, and losses to follow-up in our study, we do not believe these concerns have biased our results.

There are limitations of this work. First, given the target population of the CCC, the results are most generalizable to co-infected individuals that are currently receiving care in Canada. Also, given that FS Study data collection is ongoing, approximately one-half of the participants only had a baseline measurement as of June 2014. Subsequent analyses of these data will take advantage of longer participant follow-up. Furthermore, by using multiple imputation to address the small proportion of missing data, the non-verifiable assumption that the data were missing at random was made.

Given the sensitive nature of the information collected, there is the potential for measurement error and misclassification of self-reported variables. However, we have no reason to believe that these biases were differential between food secure and food insecure individuals. Also, the 'Other' category for province (including participants from Alberta, Saskatchewan, and Nova Scotia) holds no meaningful interpretation given the lack of homogeneity across these provinces. As more data are collected, these provinces will be analyzed separately.

Recent research related to FI has begun to stress the importance of an additional category of FI severity [52, 53], known as marginal FI (some indication of worry or an income-related barrier to adequate food access) [54]. Therefore, instead of being categorized as food secure (0-1 affirmative responses on the HFSSM), a small number of participants $(\mathrm{N}=39)$ could have been categorized in our study as experiencing marginal FI (1 affirmative response) at baseline and as food insecure in the regression models. Therefore, our study underestimates the prevalence of FI in this co-infected population. However, given the small number of participants experiencing marginal FI, we would expect little impact on our conclusions.

It is important to note that the objective was not to estimate the causal effect of one particular factor adjusted for relevant confounders. As such, modeling included a large number of independent variables and multivariate model building was informed by a consideration of statistical significance. Therefore, while insights into potential factors that may be targeted for intervention are provided, our modeling approach does not describe mechanisms whereby these factors act on FI. Also, it is possible that this approach may have resulted in collinearity. For example, education, employment, and income are all socioeconomic factors whose combined effect may be greater than any individual effect, and any individual factors effect may be affected by collinearity. Therefore, conclusions drawn from the study results are best described as hypothesis-generating. 


\section{Conclusions}

This study provides evidence regarding sociodemographic, socioeconomic, behavioral, and clinical factors associated with FI in a population of HIV-HCV co-infected individuals. FI is common in this co-infected population and the majority of food insecure participants experienced severe FI. Engagement of co-infected individuals in substance use treatments, harm reduction programs, and mental health services may mitigate FI in this vulnerable subset of the HIV-positive population. Additionally, this work generates hypotheses and provides suggestions for subsequent FIrelated research in HIV-positive populations.

Acknowledgements This study was funded by the Canadian Institutes of Health Research (CIHR) and the CIHR Canadian HIV Trials Network (CTN 264). TM is supported by the CANOC Centre Doctoral Scholarship Award, a joint program of CANOC and the CIHR Canadian HIV Trials Network (CTN 242). EEMM is supported by a 'Chercheurs boursier junior 2' career award from the Fonds de recherche du Quebec-Sante (FRQ-S). AA is supported by funding from the CIHR. MBK is supported by a 'Chercheurs nationaux' career award from the FRQ-S. The authors thank John Gill, Curtis Cooper, Valerie Martel-Laferrière, and Pierre Côté for providing feedback on the manuscript as well as Emilie Maurais, Jennifer Kocilowicz, and Leo Wong for study coordination. The Canadian Coinfection Cohort study investigators (CTN 222) are: Drs Jeff Cohen (Windsor Regional Hospital Metropolitan Campus, Windsor, ON), Brian Conway (PENDER Downtown Infectious Diseases Clinic, Vancouver, BC), Curtis Cooper (The Ottawa Hospital Research Institute, Ottawa, ON), Pierre Côté (Clinique du Quartier Latin, Montreal, QC), Joseph Cox (MUHC IDTC, Montreal General Hospital, Montreal, QC), John Gill (Southern Alberta HIV Clinic, Calgary, AB), Shariq Haider (McMaster University Medical Centre SIS Clinic, Hamilton, ON), Aida Sadr (Native BC Health Center, St Paul's Hospital, Vancouver, BC), Lynn Johnston (QEII Health Science Center for Clinical Research, Halifax, NS), Mark Hull (BC Centre for Excellence in HIV/AIDS, Vancouver, BC), Julio Montaner (St Paul's Hospital, Vancouver, BC), Erica Moodie (McGill University, Montreal, QC), Neora Pick (Oak Tree Clinic, Children's and Women's Health Centre of British Columbia, University of British Columbia, Vancouver, BC), Anita Rachlis (Sunnybrook Health Sciences Centre, University of Toronto, Toronto, ON), Danielle Rouleau (Centre Hospitalier de l'Université de Montreal, Montreal, QC), Roger Sandre (Health Sciences North - The HAVEN/ Hemophilia Program, Sudbury, ON), Joseph Mark Tyndall (Department of Medicine, Infectious Diseases Division, University of Ottawa, Ottawa ON), Marie-Louise Vachon (Centre Hospitalier Universitaire de Québec, Québec, QC), Steve Sanche (SHARE University of Saskatchewan, Saskatoon, SK), Stewart Skinner (Royal University Hospital \& Westside Community Clinic, University of Saskatchewan, Saskatoon, SK), and David Wong (University Health Network, Toronto, ON).

\section{Compliance with Ethical Standards}

Conflicts of interest The authors have no conflicts of interest to declare.

Open Access This article is distributed under the terms of the Creative Commons Attribution 4.0 International License (http://crea tivecommons.org/licenses/by/4.0/), which permits unrestricted use, distribution, and reproduction in any medium, provided you give appropriate credit to the original author(s) and the source, provide a link to the Creative Commons license, and indicate if changes were made.

\section{References}

1. Anema A, Weiser SD, Fernandes KA, et al. High prevalence of food insecurity among HIV-infected individuals receiving HAART in a resource-rich setting. AIDS Care. 2011;23(2): 221-30.

2. Kalichman SC, Cherry C, Amaral C, et al. Health and treatment implications of food insufficiency among people living with HIV/ AIDS, Atlanta, Georgia. J Urban Health. 2010;87(4):631-41.

3. Weiser SD, Bangsberg DR, Kegeles S, Ragland K, Kushel MB, Frongillo EA. Food insecurity among homeless and marginally housed individuals living with HIV/AIDS in San Francisco. AIDS Behav. 2009;13(5):841-8.

4. Normen L, Chan K, Braitstein P, et al. Food insecurity and hunger are prevalent among HIV-positive individuals in British Columbia, Canada. J Nutr. 2005;135(4):820-5.

5. Andersen SA. Core indicators of nutritional state for difficult to sample populations. J Nutr. 1990;120(Suppl. 11):1559-600.

6. Kendall A, Olson CM, Frongillo EA. Validation of the Radimer/ Cornell measures of hunger and food insecurity. J Nutr. 1995;125(11):2793-801.

7. Anema A, Globerman J, Fielden SJ, et al. High burden of food insecurity among people living with HIV/AIDS in Canada. In: First International Conference on Global Food Security. Noordwijkerhout, Netherlands, 2013 [Abstract SECU2013_0200].

8. Roshanafshar SH, Hawkins E. Health at a glance-food insecurity in Canada. Ottawa: Statistics Canada; 2015.

9. Singer AW, Weiser SD, McCoy SI. Does food insecurity undermine adherence to antiretroviral therapy? A systematic review. AIDS Behav. 2014;. doi:10.1007/s10461-014-0873-1.

10. Young S, Wheeler AC, McCoy SI, Weiser SD. A review of the role of food insecurity in adherence to care and treatment among adult and pediatric populations living with HIV and AIDS. AIDS Behav. 2014;18(Suppl 5):S505-15.

11. Wang EA, McGinnis KA, Fiellin DA, et al. Food insecurity is associated with poor virologic response among HIV-infected patients receiving antiretroviral medications. J Gen Intern Med. 2011;26(9):1012-8.

12. Anema A, Chan K, Chen Y, Weiser SD, Montaner JS, Hogg RS. Relationship between food insecurity and mortality among HIVpositive injection drug users receiving antiretroviral therapy in British Columbia, Canada. PLoS ONE. 2013;8(5):e61277.

13. Weiser SD, Frongillo EA, Ragland K, Hogg RS, Riley ED, Bangsberg DR. Food insecurity is associated with incomplete HIV RNA suppression among homeless and marginally housed HIV-infected individuals in San Francisco. J Gen Intern Med. 2009;24(1):14-20.

14. Kirkpatrick SI, Tarasuk V. Food insecurity is associated with nutrient inadequacies among Canadian adults and adolescents. J Nutr. 2007;138:604-12.

15. Anema A, Vogenthaler N, Frongillo EA, Kadiyala S, Weiser SD. Food insecurity and HIV/AIDS: current knowledge, gaps, and research priorities. Curr HIV/AIDS Rep. 2009;6:224-31.

16. Anema A, Mehra D, Weiser SD, Grede N, Vogenthaler N, Kerr T. Drivers and Consequences of Food Insecurity Among Illicit Drug Users (Chapter 20). In: Health of HIV infected people: food, nutrition and lifestyle with antiretroviral drugs. New York: Elsevier Publishing Inc; 2015. p. 359-76. 
17. Weiser SD, Young SL, Cohen CR, et al. Conceptual framework for understanding the bidirectional links between food insecurity and HIV/AIDS. Am J Clin Nutr. 2011;94(6):1729S-39S.

18. Ivers LC, Cullen KA, Freedberg KA, Block S, Coates J, Webb P. HIV/AIDS, undernutrition, and food insecurity. Clin Infect Dis. 2009;49(7):1096-102.

19. Remis RS. Modelling the incidence and prevalence of hepatitis $C$ infection and its sequelae in Canada, 2007. Ottawa: Public Health Agency of Canada; 2007.

20. Hull M, Klein MB, Shafran S, et al. CIHR Canadian HIV trials network coinfection and concurrent diseases core: Canadian guidelines for management and treatment of HIV/hepatitis C coinfection in adults. Can J Infect Dis Med Microbiol. 2013;24(4):217-38.

21. Klein MB, Rollet-Kurhajec KC, Moodie EE, et al. Mortality in HIV-hepatitis C co-infected patients in Canada compared to the general Canadian population (2003-2013). AIDS. 2014;28(13):1957-65

22. Braitstein P, Montessori V, Chan K, et al. Quality of life, depression and fatigue among persons co-infected with HIV and hepatitis C: outcomes from a population-based cohort. AIDS Care. 2005;17(4):505-15.

23. Mrus JM, Sherman KE, Leonard AC, Sherman SN, Mandell KL, Tsevat J. Health values of patients coinfected with HIV/Hepatitis C: are two viruses worse than one? Med Care. 2006;44(4): $158-66$.

24. Goulet JL, Fultz SL, McGinnis KA, Justice AC. Relative prevalence of comorbidities and treatment contraindications in HIV-mono-infected and HIV/HCV-co-infected veterans. AIDS. 2005;19(S3):S99-105.

25. Rourke SB, Sobota M, Tucker R, et al. Social determinants of health associated with hepatitis $\mathrm{C}$ co-infection among people living with HIV: results from the Positive Spaces, Healthy Places study. Open Med. 2011;5(3):e120.

26. Klein MB, Saeed S, Yang H, et al. Cohort profile: the Canadian HIV-hepatitis $\mathrm{C}$ co-infection cohort study. Int $\mathrm{J}$ Epidemiol. 2010;39(5):1162-9.

27. Health Canada. Canadian Community Health Survey, Cycle 2.2, Nutrition (2004): Income-Related Household Food Security in Canada Ottawa 2004. http://www.hc-sc.gc.ca/fn-an/surveill/nutri tion/commun/income_food_sec-sec_alim-eng.php. Accessed 3 Feb 2016.

28. Bickel G, Nord M, Price C, Hamilton W, Cook J. Guide to measuring household food security, revised 2000. Alexandria: U.S. Department of Agriculture, Food and Nutrition Service; 2000.

29. Nord M, Tarasuk V, McIntyre L, Tagtow A, Radimer K. Comparing prevalence rates of food insecurity based on Radimer/ Cornell Measures and the U.S. Household Food Security Scale. Annual Meeting of the National Association for Welfare Research and Statistics, San Diego, 2003.

30. Zhang W, O'Brien N, Forrest JI, et al. Validating a shortened depression scale (10 item CES-D) among HIV-positive people in British Columbia, Canada. PLoS ONE. 2012;7(7):e40793.

31. Rubin DB. Multiple Imputation for nonresponse in surveys. New York: Wiley; 1987.

32. Tavakol M, Dennick R. Making sense of Cronbach's alpha. Int J Med Educ. 2011;2:53-5.

33. Himmelgreen DA, Pérez-Escamilla R, Segura-Millán S, RomeroDaza N, Tanasescu M, Singer M. A comparison of the nutritional status and food security of drug-using and non-drug-using Hispanic women in Hartford, Connecticut. Am J Phys Anthropol. 1998;107(3):351-61.

34. Campa A, Yang Z, Lai S, et al. HIV-related wasting in HIVinfected drug users in the era of highly active antiretroviral therapy. Clin Infect Dis. 2005;41:1179-85.
35. Vasarhelyi K, Brandson EK, Palmer AK, et al. Home is where the HAART is: an examination of factors affecting neighbourhood perceptions among people with HIV/AIDS on antiretroviral therapy. AIDS Care. 2011;23(2):245-51.

36. Rhodes T, Singer M, Bourgois P, Friedman SR, Strathdee SA. The social structural production of HIV risk among injecting drug users. Soc Sci Med. 2005;61(5):1026-44.

37. Rhodes T. The 'risk environment': a framework for understanding and reducing drug-related harm. Int $J$ Drug Policy. 2002;13:85-94.

38. Santolaria-Fernández FJ, Gómez-Sirvent JL, González-Reimers CE, et al. Nutritional assessment of drug addicts. Drug Alcohol Depend. 1995;38:11-8.

39. Anema A, Wood E, Weiser SD, Qi J, Montaner JS, Kerr T. Hunger and associated harms among injection drug users in an urban Canadian setting. Subst Abuse Treat Prev Policy. 2010;5:20.

40. Kertesz SG, Khodneva Y, Richman J, et al. Trajectories of drug use and mortality outcomes among adults followed over 18 years. J Gen Intern Med. 2012;27(7):808-16.

41. van Ameijden EJC, van den Hoek JAR, Hartgers C, Coutinho RA. Risk factors for the transition from noninjection to injection drug use and accompanying AIDS risk behavior in a cohort of drug users. Am J Epidemiol. 1994;139(12):1153-63.

42. Strike C, Rudzinski K, Patterson J, Millson M. Frequent food insecurity among injection drug users: correlates and concerns. BMC Public Health. 2012;12:1058.

43. Kalichman SC, Hernandez D, Kegler C, Cherry C, Kalichman MO, Grebler T. Dimensions of poverty and health outcomes among people living with HIV infection: limited resources and competing needs. J Community Health. 2015;40(4):702-8.

44. Tarasuk V, Dachner N, Poland B, Gaetz S. Food deprivation is integral to the 'hand to mouth' existence of homeless youths in Toronto. Public Health Nutr. 2009;12(9):1437-42.

45. Dachner N, Tarasuk V. Homeless "squeegee kids": food insecurity and daily survival. Soc Sci Med. 2002;54:1039-49.

46. Romero-Daza N, Himmelgreen DA, Pérez-Escamilla R, SeguraMillán S, Singer M. Food habits of drug-using Puerto Rican women in inner-city Hartford. Med Anthropol. 1999;18(3): 281-98.

47. Lux V, Kendler KS. Deconstructing major depression: a validation study of the DSM-IV symptomatic criteria. Psychol Med. 2010;40(10):1679-90.

48. Belle D, Doucet J. Poverty, inequality, and discrimination as sources of depression among U.S. women. Psychol Women Q. 2003;27:101-13.

49. Hamelin A-M, Habicht J-P, Beaudry M. Food insecurity: consequences for the household and broader social implications. J Nutr. 1999;129:525S-8S.

50. Klein MB, Rollet KC, Saeed S, et al. HIV and hepatitis $\mathrm{C}$ virus coinfection in Canada: challenges and opportunities for reducing preventable morbidity and mortality. HIV Med. 2013;14(1): $10-20$.

51. Anema A, Fielden SJ, Castleman T, Grede N, Heap A, Bloem M. Food security in the context of HIV: towards harmonized definitions and indicators. AIDS Behav. 2014;18(Suppl 5):S476-89.

52. Cook JT, Black M, Chilton M, et al. Are food insecurity's health impacts underestimated in the U.S. population? Marginal food security also predicts adverse health outcomes in young U.S. children and mothers. Adv Nutr. 2013;4(1):51-61.

53. Coleman-Jensen AJ. U.S. food insecurity status: toward a refined definition. Soc Indic Res. 2009;95(2):215-30.

54. Tarasuk V, Mitchell A, Dachner N. Household food insecurity in Canada, 2012. Toronto: Research to identify policy options to reduce food insecurity (PROOF), 2014. 